\title{
Failure Assessment for the High-Strength Pipelines with Constant-Depth Circumferential Surface Cracks
}

\author{
X. Liu, ${ }^{1}$ Z. X. Lu, ${ }^{1}$ Y. Chen, ${ }^{2,3}$ Y. L. Sui, ${ }^{4}$ and L. H. Dai $\mathbb{D}^{2,3}$ \\ ${ }^{1}$ Institute of Solid Mechanics, Beijing University of Aeronautics and Astronautics, Beijing 100191, China \\ ${ }^{2}$ State Key Laboratory of Nonlinear Mechanics, Institute of Mechanics, Chinese Academy of Sciences, Beijing 100190, China \\ ${ }^{3}$ School of Engineering Science, University of Chinese Academy of Sciences, Beijing 101408, China \\ ${ }^{4}$ Pipeline Research Institute of China National Petroleum Corporation, Langfang 065000, China \\ Correspondence should be addressed to L. H. Dai; lhdai@lnm.imech.ac.cn
}

Received 22 September 2017; Revised 24 November 2017; Accepted 4 December 2017; Published 18 February 2018

Academic Editor: Philip Eisenlohr

Copyright (c) 2018 X. Liu et al. This is an open access article distributed under the Creative Commons Attribution License, which permits unrestricted use, distribution, and reproduction in any medium, provided the original work is properly cited.

\begin{abstract}
In the oil and gas transportation system over long distance, application of high-strength pipeline steels can efficiently reduce construction and operation cost by increasing operational pressure and reducing the pipe wall thickness. Failure assessment is an important issue in the design, construction, and maintenance of the pipelines. The small circumferential surface cracks with constant depth in the welded pipelines are of practical interest. This work provides an engineering estimation procedure based upon the GE/EPRI method to determine the J-integral for the thin-walled pipelines with small constant-depth circumferential surface cracks subject to tension and bending loads. The values of elastic influence functions for stress intensity factor and plastic influence functions for fully plastic $J$-integral estimation are derived in tabulated forms through a series of three-dimensional finite element calculations for different crack geometries and material properties. To check confidence of the J-estimation solution in practical application, $J$-integral values obtained from detailed finite element (FE) analyses are compared with those estimated from the new influence functions. Excellent agreement of FE results with the proposed J-estimation solutions for both tension and bending loads indicates that the new solutions can be applied for accurate structural integrity assessment of high-strength pipelines with constant-depth circumferential surface cracks.
\end{abstract}

\section{Introduction}

The growing demand for energy and natural resources has been pushing exploration and production activities of oil and natural gas. In particular, application of thin-walled high-strength steel has become a trend in the oil and gas transportation system over long distance, which can improve the transportation efficiency by high-pressure operation and reduce the pipe laying cost by reducing the wall thickness of pipes $[1,2]$. Research projects have then been focused on the development of API grades X80 and X100 and more recently to grade X120 [1]. The high-grade pipeline steels have high yield-to-ultimate tensile strength ratio, which means they have relatively low strainhardening ability. For the high-strength pipelines adopted in industries, the mean diameter-to-thickness ratio $D / t$ generally ranges from 50 to 100 , such as the grade API 5L X80 steel applied on TransCanada system.
The long-distance oil and gas pipes are joined by girth weld. Common failures in pipelines result primarily from the weld defects. The failure assessment of crack-like flaws is an important issue in design and maintenance of the pipeline systems. Specifically, the fracture parameter $J$-integral has been widely used in the structural integrity assessment of defective pipes. Full three-dimensional finite element (FE) analyses can provide accurate results for the fracture response. However, FE analyses require large computational time, expertise, and resources, which make the numerical computation quite expensive to be used routinely; hence, they are not suitable for engineering structural integrity assessment. Therefore, the simplified $J$-estimation scheme with much less computational cost is highly desired from the view of engineering application.

Based upon the fully plastic $J$-integral solution developed by Shih and Hutchinson [3], Kumar et al. [4] introduced the 
widely known GE/EPRI J-estimation approach for twodimensional geometries. Afterwards, the original work was extended by various researchers [5-14] to include additional geometries and loading conditions. Another popular J-estimation method is the reference stress approach which adopts the plastic limit load as the reference stress [15]. Based upon the FE results for pipes with varying geometries under different loading conditions, it was proposed that the reference stress could be redefined by an "optimized reference load" (rather than the plastic limit load) [16-19]. This method is termed as an enhanced reference stress method and can improve the accuracy in $J$ estimation. However, it should be noted that these works mainly cover the cases of cracked pipes having mean diameter-to-thickness ratio $(D / t)$ not more than 40 , while the values of $D / t$ for high-strength pipelines are normally larger than 50 .

To verify the applicability limit of the existing GE/EPRI method with regard to the diameter-to-thickness ratio $D / t$, Cho et al. [20] have explored the J-estimation schemes for semielliptical surface-cracked pipes with $D / t$ ranging from 10 to 120. Park et al. [21] have performed several FE analyses for pipes with a short circumferential through-wall crack. As pointed by those previous works [20-22], an application of existing solutions would result in inaccurate structural integrity assessment results when thin-walled pipes with large diameter are considered. If existing GE/EPRI solution, whose applicability is $D / t \leq 40$, is directly extrapolated to thin-walled pipes with $D / t>60$, the $J$-integral would be nonconservative compared with the FE results [20, 21]. Underestimation of the crack-driving force might be very dangerous in the engineering failure assessment, which needs to be avoided. Therefore, extension of the estimation methods is urgently required for thin-walled pipes. Furthermore, in most of previous works, the surface cracks are usually modeled as elliptical configuration. The surface cracks with constant depth might represent well the weld defects commonly observed in pipelines [23]. Moreover, based upon the limits routinely adopted in design as well as nondestructive testing examination, such as API 1104 [24], small cracks are often a major concern for the welded pipes with large diameter. In this content, J-estimation solutions for thin-walled pipes with small constant-depth cracks need to be developed to overcome the limitations of the existing solutions.

This paper focuses on extending J-estimation solutions for high-strength pipelines with small constant-depth cracks. A series of elastic and elastic-plastic FE analyses for the thin-walled pipes with $D / t$ ranging from 50 to 100 under tension and bending loads are conducted in this paper. The analyses involve small constant-depth cracks with crack depth-to-thickness ratio a/t ranging $0.1-0.4$ and normalized crack length $\theta / \pi$ ranging $0.01-0.08$ for pipes with different strain-hardening properties. By analyzing the FE results, the values of elastic influence functions for elastic stress intensity factor $K$ and plastic influence functions for fully plastic $J$-integral are proposed in tabulated forms based upon GE/EPRI estimation method. To show the efficiency of the estimation method for idealized Ramberg-Osgood material, J-integral values obtained from the new elastic and plastic influence functions are compared with those from detailed three-dimensional FE analyses. Moreover, to check confidence of the J-estimation solution in practical application, elastic-plastic FE analyses are also conducted using experimental stress-strain data for three typical grade pipeline steels.

\section{The GE/EPRI Method for $J$ Estimation}

2.1. The EPRI Methodology. To estimate elastic-plastic $J$-values for a cracked body, the GE/EPRI engineering method $[3,4]$ was developed based on FE solutions using deformation plasticity theory. The method assumes that the constitutive law for the materials can be characterized by the Ramberg-Osgood model:

$$
\frac{\varepsilon}{\varepsilon_{0}}=\frac{\sigma}{\sigma_{0}}+\alpha\left(\frac{\sigma}{\sigma_{0}}\right)^{n},
$$

where $\sigma$ is the true stress, $\varepsilon$ is the true strain, $\sigma_{0}$ is the yield stress, $E$ is the elastic modulus, $\varepsilon_{0}=\sigma_{0} / E$ is the corresponding reference strain, $\alpha$ is a dimensionless constant, and $n$ defines the strain-hardening exponent.

The GE/EPRI estimation method evolved from the two limiting cases of elastic and fully plastic conditions. The elastic-plastic $J$-integral is split into elastic and plastic components as

$$
J=J_{e}\left(a_{e}\right)+J_{p}
$$

where the subscript " $e$ " denotes the elastic part of $J$, adjusted by a plastic zone correction using the effective crack length $a_{e}$, and " $p$ " refers to plastic contributions. The elastic component $J_{e}$ can be expressed via the stress intensity factor $K$ by

$$
J_{e}=\frac{K^{2}}{E^{\prime}},
$$

where $E^{\prime}=E$ for plane stress condition and $E^{\prime}=E /\left(1-\nu^{2}\right)$ for plane strain condition, with $\nu$ representing the Poisson ratio. Irwin [25] proposed that the plastic zone corrected crack length $a_{e}$ can be obtained by

$$
a_{e}=a+\frac{1}{\beta \pi}\left(\frac{K(a)}{\sigma_{0}}\right)^{2},
$$

where $a$ is the crack length, $\beta=2$ for plane stress, and $\beta=6$ for plane strain conditions.

In 1976, Shih and Hutchinson [3] developed a new method for fully plastic $J$-integral solutions. Upon consideration of a fully plastic cracked structure in which the elastic strains $\varepsilon_{e}$ are vanishingly small compared with the plastic strains $\varepsilon_{p}$, the material defined by (1) follows a pure powerlaw stress-strain curve:

$$
\frac{\varepsilon_{p}}{\varepsilon_{0}}=\alpha\left(\frac{\sigma}{\sigma_{0}}\right)^{n} .
$$

Under such assumption and close to the crack tip, the crack tip stress fields are given by the HRR singularity [26] 

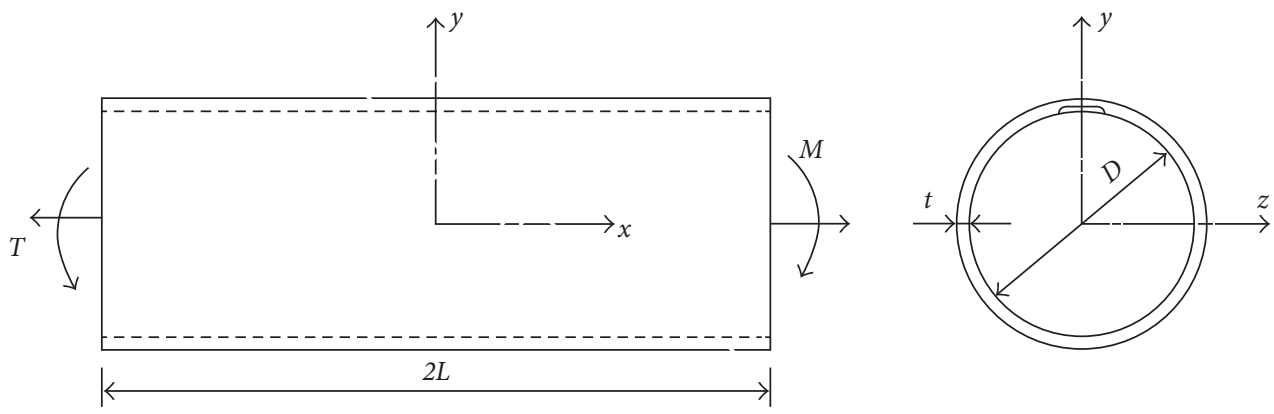

(a)

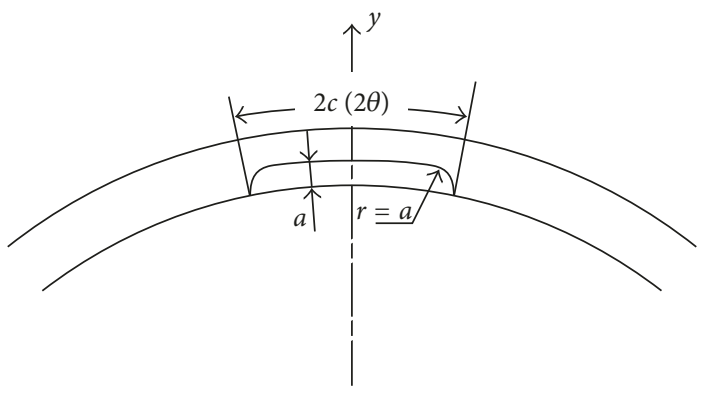

(b)

FIgURE 1: (a) The geometrical dimension of the pipe with a circumferential surface crack. (b) Geometry of the surface crack.

$$
\frac{\sigma_{i j}}{\sigma_{0}}=\left(\frac{J_{p}}{\alpha \sigma_{0} \varepsilon_{0} I_{n} r}\right)^{1 /(n+1)} \tilde{\sigma}_{i j}(n, \varphi),
$$

where $(r, \varphi)$ are polar coordinates centered at the crack tip, $I_{n}$ is an integration constant, and $\tilde{\sigma}_{i j}(n, \varphi)$ are dimensionless stress functions. The HRR equation can be rewritten in the form of $J$-integral:

$$
J_{p}=\alpha \sigma_{0} \varepsilon_{0} I_{n} r\left(\frac{\sigma_{i j}}{\sigma_{0}}\right)^{n+1} \widetilde{\sigma}_{i j}^{n+1} .
$$

With the application of Ilyushin's theorem [27] that the fully plastic stresses are simply proportional to the applied load $P$, the fully plastic $J$ given by (7) can be expressed in terms of the applied load as

$$
J_{p}=\alpha b \sigma_{0} \varepsilon_{0} h_{1}\left(\frac{a}{W}, l, n\right)\left(\frac{P}{P_{\text {ref }}}\right)^{n+1},
$$

where $W$ is the component width, $b=W-a$ defines the uncracked ligament, $\iota$ represents additional characteristic length for the component, and $h_{1}$ is the plastic influence function dependent on crack size, specimen geometry, and strain-hardening exponent. In (8), the generalized load is normalized by a reference load $P_{\text {ref }}$ which may be freely chosen provided it is proportional to $\sigma_{0}$ but is often identified with the plastic limit load of the cracked component $P_{L}$.

2.2. Extension to Circumferentially Cracked Pipes. Figure 1 shows the relevant pipe and crack dimensions for circumferentially cracked pipes subjected to tensile load $T$ and bending moment $M$. The circumferential surface crack in this work is assumed to be of constant depth $a$ and length $2 c$ with an end radius equal to the crack depth (as displayed in Figure 1). For the thin-walled pipes with large diameter, the circumferential crack angle $2 \theta$ is related to the crack length by

$$
\theta=2 c / D
$$

For circumferential surface cracks, the stress intensity factor can be expressed as

$$
K=\sigma \sqrt{\pi a} F,
$$

where $F$ is the elastic influence function and $\sigma$ denotes the applied stress due to axial loading or bending moment by the following equation:

$$
\sigma= \begin{cases}\frac{T}{2 \pi R t} & \text { for tension, } \\ \frac{4 M R}{\pi\left(R_{o}^{4}-R_{i}^{4}\right)} & \text { for pure bending, }\end{cases}
$$

where $t$ is the pipe wall thickness, $R$ denotes the mean radius $(R=D / 2)$, and $R_{o}$ and $R_{i}$ are the external and internal radii, respectively. Once the elastic influence function $F$ is determined, the elastic term of $J, J_{e}$, can be calculated using (3). Then, the effective crack depth is obtained by (4). Noting that pipes with circumferential part-through defects can be in between plane stress and plane strain conditions, the plane strain constant of 6 in (4) is valid only when the plasticity is confined within a dominantly elastically behaving body $[16,17]$. On the other hand, if the plasticity effect is much more 
significant even below the widespread plasticity level, the plane stress constant of 2 is retained [17]. By FE analyses for the small circumferential part-through defects, an empirical value of constant parameter $\beta$ is adopted in this work $(\beta=2$ for pipes with $n=10$ and $\beta=3$ for pipes with $n \geq 15$ ).

To obtain the fully plastic part of the $J$-integral for the circumferentially cracked pipes, (8) can be rewritten as

$$
J_{p}=\alpha b \sigma_{0} \varepsilon_{0} h_{1}\left(\frac{a}{t}, \frac{\theta}{\pi}, \frac{D}{t}, n\right)\left(\frac{P}{P_{L}}\right)^{n+1},
$$

where the uncracked ligament is $b=t-a$ and the generalized load $P_{L}$ is either the limit tensile load $T_{L}$ or the plastic limit moment $M_{L}$, given by [28]. The tensile load $T_{L}$ and the plastic limit moment $M_{L}$ are expressed as

$$
\begin{aligned}
& T_{L}=2 \pi R t \sigma_{0}\left[1-\frac{\theta}{\pi} \frac{a}{t}-\frac{2}{\pi} \sin ^{-1}\left(\frac{a}{t} \frac{\sin \theta}{2}\right)\right], \\
& M_{L}=4 R^{2} t \sigma_{0}\left[\cos \left(\frac{a \theta}{2 t}\right)-\frac{a \sin \theta}{2 t}\right] .
\end{aligned}
$$

\section{Finite Element Analysis}

A series of parametric finite element simulations of circumferentially cracked pipes subjected to tensile load and bending moment have been conducted. The thin-walled pipes with large diameter are of main concern; here, two typical mean diameter-to-thickness ratios are considered, namely, $D / t=50$ and 100. Pipe wall thickness $t$ is fixed to be $20 \mathrm{~mm}$ in the present work. As the weld pass height governs the flaw sizes in girth-welded pipelines, which is typically $2-6 \mathrm{~mm}$ in height [29], the values of crack depth-to-thickness ratio a/t are rationally selected as $a / t=0.1,0.2,0.3$, and 0.4 in this work. Small cracks $(2 c \leq 250 \mathrm{~mm})$ are of practical interest in girth-welded pipelines [30]; therefore, the normalized crack lengths have been chosen as $\theta / \pi=0.01$ and 0.08 for pipes with $D / t=50$ and $\theta / \pi=0.01$ and 0.04 for pipes with $D / t=100$. To make the end effects on the computed fracture parameter J-integral negligible, the total length of a pipe segment $2 L$ is assumed to be six times the outer diameter [23].

In this paper, all analyses were performed by the commercial FE program, ABAQUS. Figure 2 shows a typical finite element mesh for the thin-walled pipe with $a / t=0.2$, $\theta / \pi=0.01$, and $D / t=100$. Similar meshes were employed for models with other crack depths and crack lengths. Considering the symmetry conditions, only one-quarter of the pipe was modeled to improve the computational efficiency as shown in Figure 2. Symmetry boundary conditions were prescribed on the two surfaces whose normal direction is $z$ axis ( $z=0$ in Figure 1(a)) as well as on the midsection of the pipe ( $x=0$ in Figure 1(a), except the crack face). A reference point is defined at the uncracked end of the model and tied to all nodes at that end via the MPC (multipoint constraint). Tension is applied by specifying axial displacement to the reference node, and bending is applied by imposing a rotation to the reference point. The applied load is determined from the force acting on the reference point.

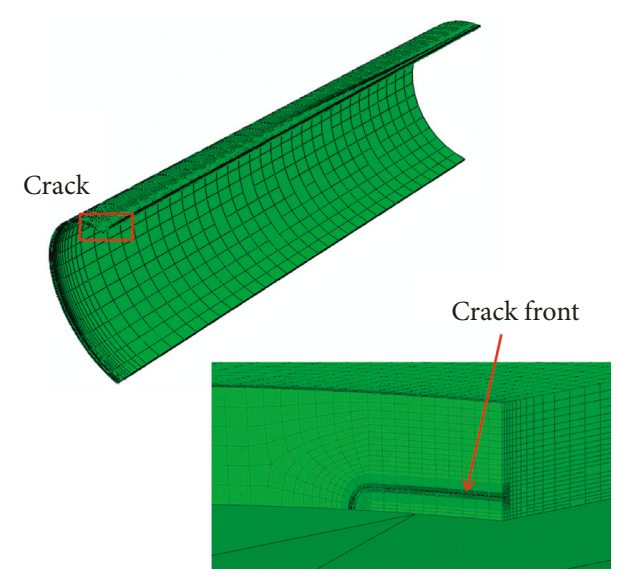

FIGURE 2: Finite element mesh for the pipe with $a / t=0.2, \theta / \pi=0.01$, and $D / t=100$.

Elastic and elastic-plastic FE analyses were performed to calculate the elastic fracture parameter $K$ and the elasticplastic fracture parameter $J$-integral at the deepest point of the surface cracks. For elastic analyses, an isotropic material was assumed with Young' modulus $E=200 \mathrm{GPa}$ and Poisson' ratio $\nu=0.3$. For elastic-plastic analyses, the material was assumed to follow the Ramberg-Osgood relation described by (1). In the parametric analyses, yield stress and dimensionless constant are fixed to $\sigma_{0}=400 \mathrm{MPa}$ and $\alpha=1$. The hardening exponent of $n=10$ corresponds to pipeline steels of grade API 5L X60 to X65, and $n=20$ represents API $5 \mathrm{~L}$ X80 or above $[14,31]$. Therefore, three different values of the strain-hardening index $n$ are chosen, that is, $n=10,15$, and 20 .

The values of $J$-integral are calculated from the FE results using a domain integral method, as a function of applied load. Noting that the overall deviation of the J-integral values, respectively, calculated from ten contours was less than a few percent, the confidence of the FE results was gained by the path independence of the $J$-integral values. Thus, the $J$-integral values were calculated from the mean of second to tenth contours after excluding the one immediately surrounding the crack tip. For elastic analyses, the calculated $J$-integral values were converted to elastic fracture parameters $K$ by (3).

To make further confidence in the accuracy of the numerical results, elastic and plastic FE results were compared with existing solution. For constant-depth surface cracks, the applicability of Zahoor's solution [5] is $10 \leq D / t \leq 20$ and $0.05 \leq \theta / \pi \leq 1$. Figure 3 shows comparisons of $F$ values obtained from the FE analyses and Zahoor's solution [5] for pipes with $a / t=0.4$ and $\theta / \pi=0.08$. Figure 4 compares the numerical $J$-integral values by detailed $\mathrm{FE}$ analysis with Zahoor's solution [5]. As shown in Figure 3, the difference between the values of the elastic influence function $F$ from FE analyses and those from Zahoor [5] is minor when $D / t$ is around 20. The J-integral values from FE and Zahoor's solution [5] are found to be consistent with each other for the relatively thick-walled pipe with $D / t=20$ as displayed in Figure 4 . Therefore, the FE analyses are sufficiently validated 


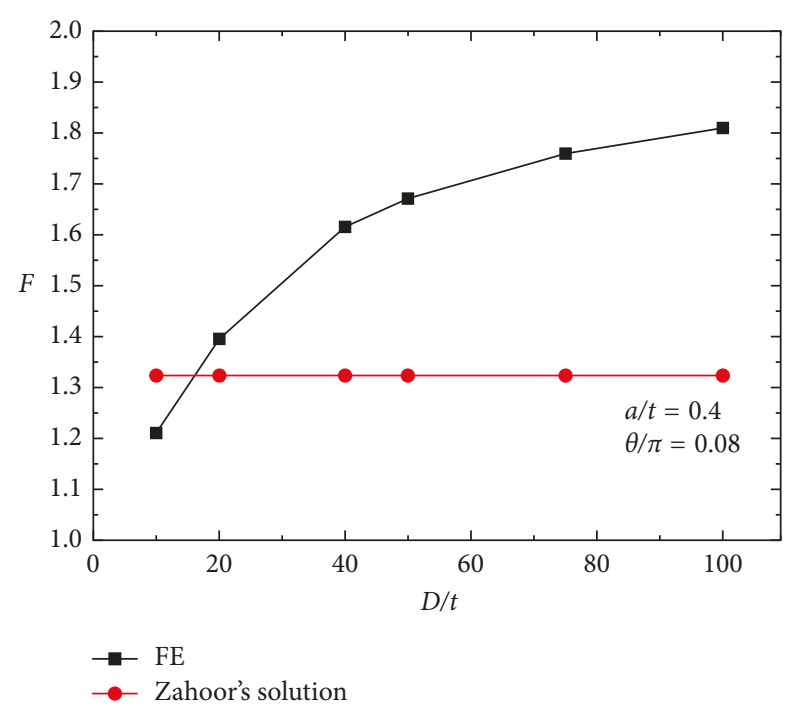

(a)

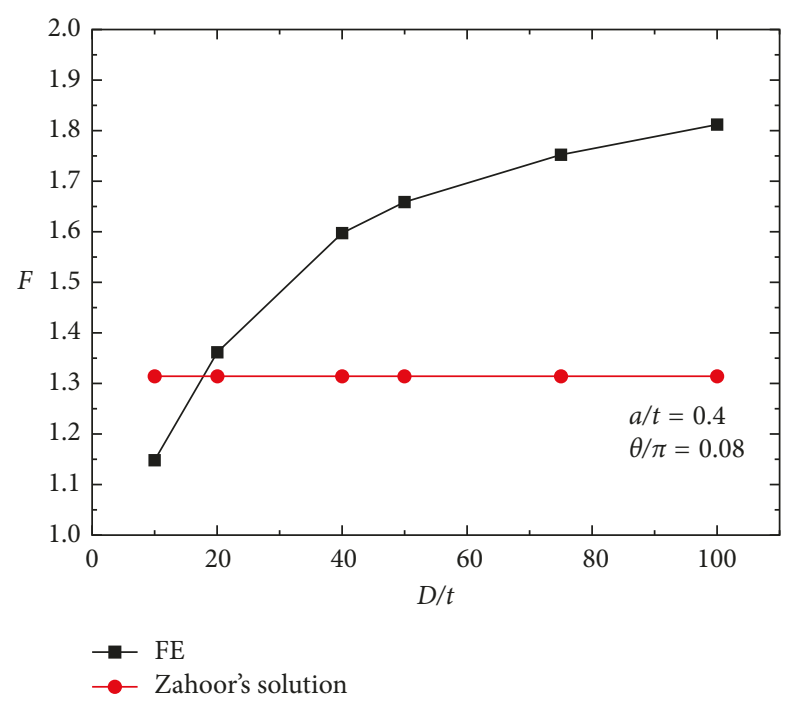

(b)

Figure 3: Comparison of $F$ values for pipes with $a / t=0.4$ and $\theta / \pi=0.08$ : (a) tension; (b) bending.

for this study. On the other hand, it can be seen from Figure 3 that the deviation of the elastic influence function $F$ by FE analyses from those of Zahoor [5] increases with the growth of $D / t$ for pipes with $D / t>20$, which means a new elastic influence function needs to be proposed for the application to the thin-walled pipes. To check the applicability of the existing GE/EPRI method with regard to $D / t$, elastic-plastic FE analysis is also carried out for thin-walled pipes with $D / t=50$. Figure 5 shows comparisons of $J$-integral versus applied load obtained from the FE analyses and Zahoor's solution [20] for thin-walled pipes with $D / t=50$. As shown in Figure 5, the existing GE/EPRI solution underestimates the $J$-integral when thin-walled pipes with small cracks are considered. Therefore, an extension of existing GE/EPRI method is conducted in the following section for the thinwalled pipes with small cracks.

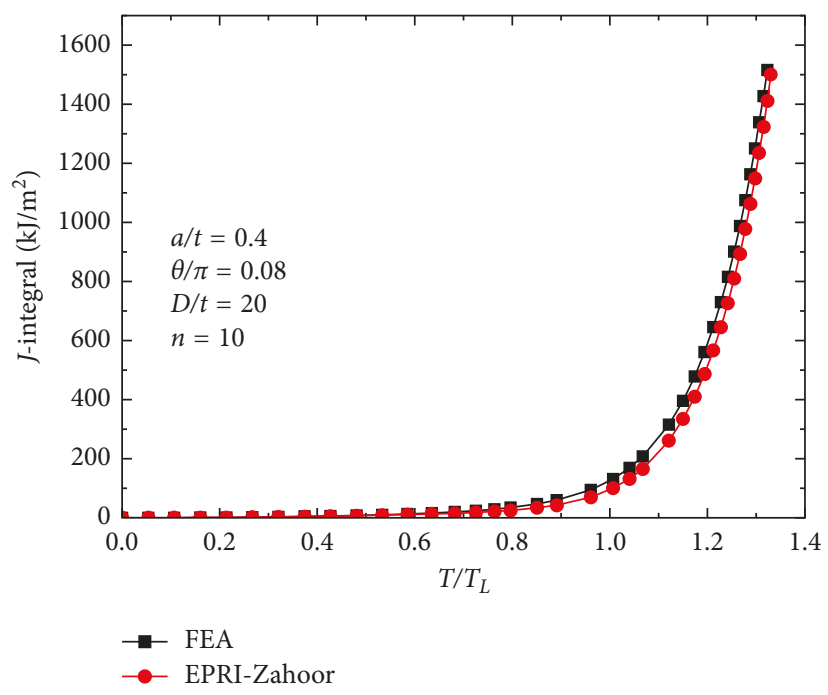

FIgURE 4: Comparison of $J$-integral values for relatively thickwalled pipes under tension with $D / t=20, a / t=0.4$, and $\theta / \pi=0.08$.

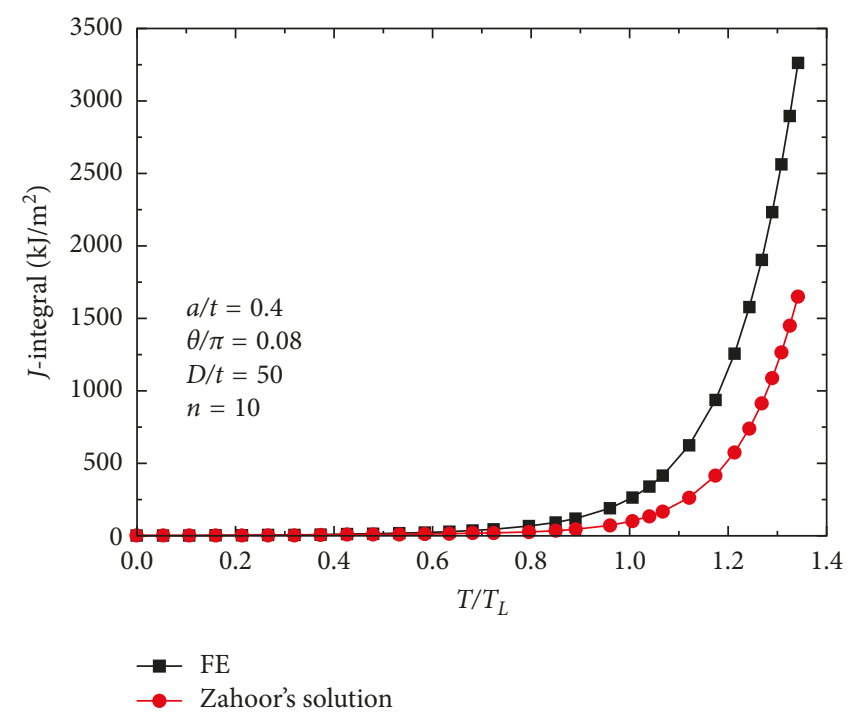

Figure 5: Comparison of $J$-integral values for thin-walled pipes under tension with $D / t=50, a / t=0.4$, and $\theta / \pi=0.08$.

TABLE 1: Tabulated values of $F$ for thin-walled pipes under tension.

\begin{tabular}{lccccc}
\hline \multirow{2}{*}{$D / t$} & $\theta / \pi$ & 0.1 & 0.2 & 0.3 & 0.4 \\
\hline \multirow{2}{*}{50} & 0.01 & 1.137 & 1.130 & 1.089 & 1.035 \\
& 0.08 & 1.177 & 1.296 & 1.465 & 1.671 \\
\multirow{2}{*}{100} & 0.01 & 1.153 & 1.228 & 1.293 & 1.335 \\
& 0.04 & 1.174 & 1.312 & 1.502 & 1.740 \\
\hline
\end{tabular}

\section{Results and Discussion}

4.1. New Elastic Influence Function F and Plastic Influence Function $h_{1}$. By performing the elastic FE analyses for the thin-walled pipes with $D / t=50$ and 100 , the values of $F$ for the stress intensity factor under tension are given in Table 1. 
TABLE 2: Tabulated values of $F$ for thin-walled pipes under bending.

\begin{tabular}{lccccc}
\hline \multirow{2}{*}{$D / t$} & $\theta / \pi$ & 0.1 & 0.2 & 0.3 & 0.4 \\
\hline \multirow{2}{*}{50} & 0.01 & 1.123 & 1.118 & 1.086 & 1.029 \\
& 0.08 & 1.162 & 1.281 & 1.451 & 1.658 \\
\multirow{2}{*}{100} & 0.01 & 1.154 & 1.228 & 1.295 & 1.339 \\
& 0.04 & 1.174 & 1.313 & 1.504 & 1.743 \\
\hline
\end{tabular}

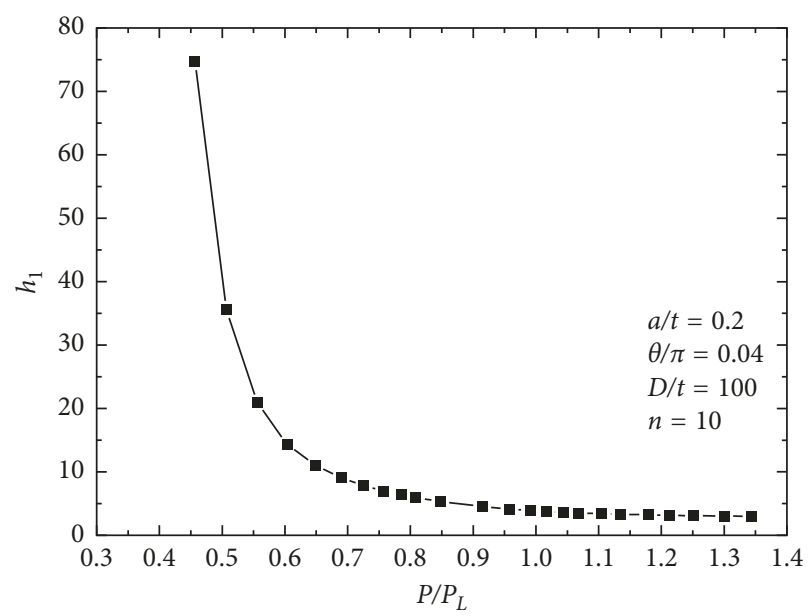

(a)

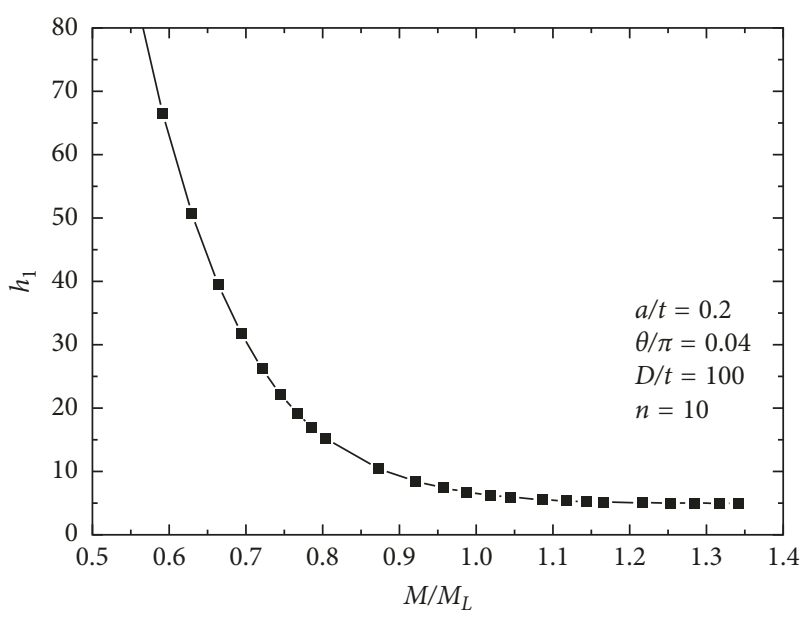

(b)

FIGURE 6: Variation of the FE results for $h_{1}$ with the load magnitude for $a / t=0.2, \theta / \pi=0.01$, and $D / t=100$ : (a) tension; (b) bending.

Results of $F$ for these pipes under bending are tabulated in Table 2.

For circumferentially cracked pipes, new plastic influence function $h_{1}$ is calculated using the equation for fully plastic part of the J-integral in (12), which is rewritten as

$$
h_{1}\left(\frac{a}{t}, \frac{\theta}{\pi}, \frac{D}{t}, n\right)=\frac{J-J_{e}}{\alpha b \sigma_{0} \varepsilon_{0}\left(P / P_{L}\right)^{n+1}} .
$$

Note that the calculated values of $h_{1}$ depend on the load magnitude, as shown in Figure 6. As $h_{1}$ represents a fully
TABLE 3: Tabulated values of $h_{1}$ for thin-walled pipes under tension.

\begin{tabular}{|c|c|c|c|c|c|c|}
\hline \multirow{2}{*}{$n$} & \multirow{2}{*}{$D / t$} & \multirow{2}{*}{$\theta / \pi$} & \multicolumn{4}{|c|}{$a / t$} \\
\hline & & & 0.1 & 0.2 & 0.3 & 0.4 \\
\hline \multirow{4}{*}{10} & \multirow{2}{*}{50} & 0.01 & 0.6401 & 1.673 & 3.187 & 4.886 \\
\hline & & 0.08 & 0.6904 & 2.454 & 6.738 & 12.31 \\
\hline & \multirow{2}{*}{100} & 0.01 & 0.6975 & 2.322 & 5.442 & 9.957 \\
\hline & & 0.04 & 0.7293 & 2.995 & 9.171 & 19.98 \\
\hline \multirow{4}{*}{15} & \multirow{2}{*}{50} & 0.01 & 0.6895 & 1.858 & 3.651 & 5.689 \\
\hline & & 0.08 & 0.7281 & 2.744 & 7.354 & 11.87 \\
\hline & \multirow{2}{*}{100} & 0.01 & 0.7651 & 2.707 & 6.594 & 11.74 \\
\hline & & 0.04 & 0.7944 & 3.592 & 11.36 & 20.83 \\
\hline \multirow{4}{*}{20} & \multirow{2}{*}{50} & 0.01 & 0.7351 & 2.008 & 4.006 & 6.322 \\
\hline & & 0.08 & 0.7545 & 3.011 & 8.066 & 11.66 \\
\hline & \multirow{2}{*}{100} & 0.01 & 0.8225 & 3.034 & 7.539 & 13.13 \\
\hline & & 0.04 & 0.8437 & 4.135 & 13.19 & 22.37 \\
\hline
\end{tabular}

TABLE 4: Tabulated values of $h_{1}$ for thin-walled pipes under bending.

\begin{tabular}{|c|c|c|c|c|c|c|}
\hline \multirow{2}{*}{$n$} & \multirow{2}{*}{$D / t$} & \multirow{2}{*}{$\theta / \pi$} & \multicolumn{4}{|c|}{$a / t$} \\
\hline & & & 0.1 & 0.2 & 0.3 & 0.4 \\
\hline \multirow{4}{*}{10} & \multirow{2}{*}{50} & 0.01 & 0.8860 & 2.445 & 4.673 & 7.184 \\
\hline & & 0.08 & 1.006 & 3.716 & 10.06 & 17.89 \\
\hline & \multirow{2}{*}{100} & 0.01 & 1.103 & 3.555 & 8.137 & 14.81 \\
\hline & & 0.04 & 1.230 & 4.947 & 14.48 & 31.52 \\
\hline \multirow{4}{*}{15} & \multirow{2}{*}{50} & 0.01 & 0.9620 & 2.725 & 5.410 & 8.481 \\
\hline & & 0.08 & 1.068 & 4.166 & 10.81 & 14.29 \\
\hline & \multirow{2}{*}{100} & 0.01 & 1.209 & 4.186 & 9.974 & 17.32 \\
\hline & & 0.04 & 1.349 & 5.819 & 17.74 & 34.93 \\
\hline \multirow{4}{*}{20} & \multirow{2}{*}{50} & 0.01 & 1.077 & 3.016 & 6.123 & 9.777 \\
\hline & & 0.08 & 1.177 & 4.933 & 12.91 & 15.43 \\
\hline & \multirow{2}{*}{100} & 0.01 & 1.340 & 4.824 & 11.71 & 20.05 \\
\hline & & 0.04 & 1.481 & 6.936 & 21.13 & 38.04 \\
\hline
\end{tabular}

plastic condition, the values of $h_{1}$ in (14) are taken at sufficiently high load level in which plastic strains dominate elastic strains. Table 3 lists the values of the plastic function $h_{1}$ for the circumferentially cracked pipes with varying material properties under tension. Results of $h_{1}$ for the pipes under bending are tabulated in Table 4.

An illustrative validation of the GE/EPRI procedure for $J$ integral estimation of the idealized Ramberg-Osgood material is presented here. By using the GE/EPRI method with newly proposed elastic and plastic influence functions, the values of elastic-plastic J-integral are estimated and compared with those from FE results. Figure 7 refers to the pipes under tension having $D / t=100, a / t=0.2$, and $\theta / \pi=0.01$. Figure 8 shows the results for the pipes with the same configuration under bending. In Figures 7 and 8, new GE/EPRI means the GE/EPRI method with newly generated elastic and plastic influence functions. As shown in these two figures, the results of GE/EPRI estimation method with new elastic and plastic influence functions agree well with the FE results. Therefore, by deriving the effective values of influence functions, $J$-estimation procedure based upon the GE/EPRI method can be applied to the high-strength pipelines with small constant-depth cracks, which is of practical interest. 


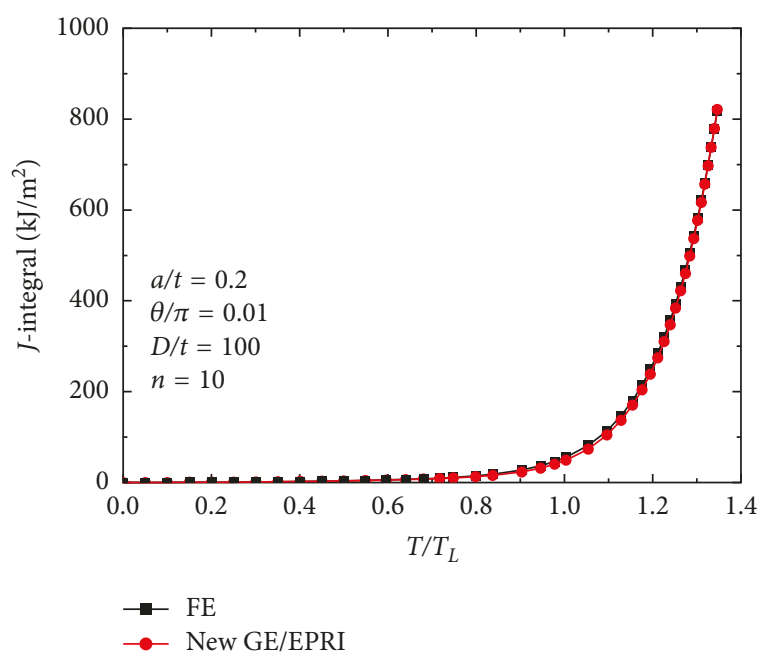

(a)

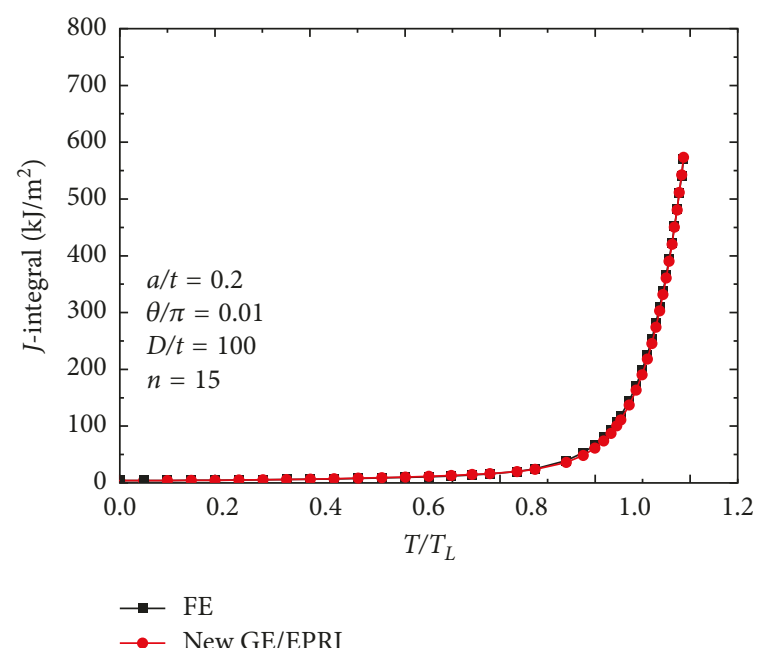

(b)

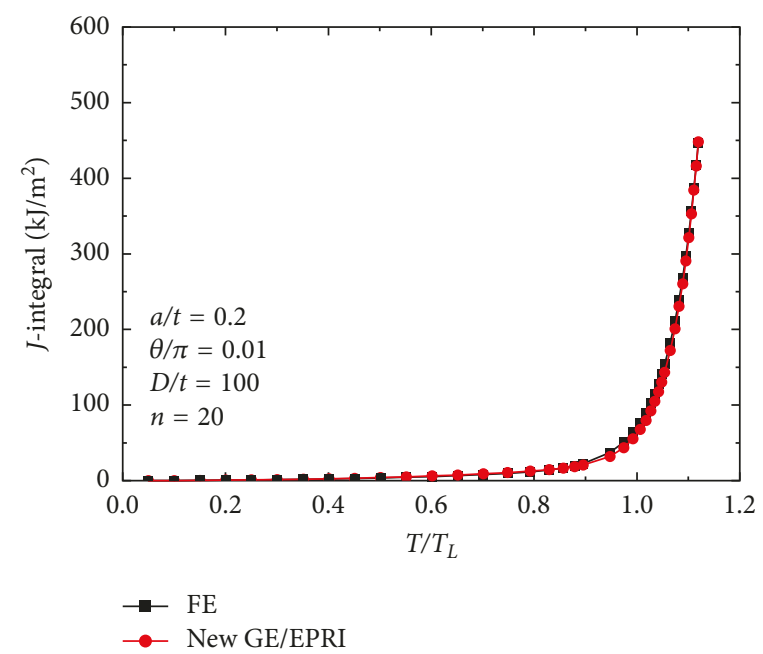

(c)

FIGURE 7: Comparison of $J$-integral estimated by using new elastic and plastic influence functions with FE results for thin-walled pipes under tension having $D / t=100, a / t=0.2$, and $\theta / \pi=0.01$ : (a) $n=10$; (b) $n=15$; (c) $n=20$.

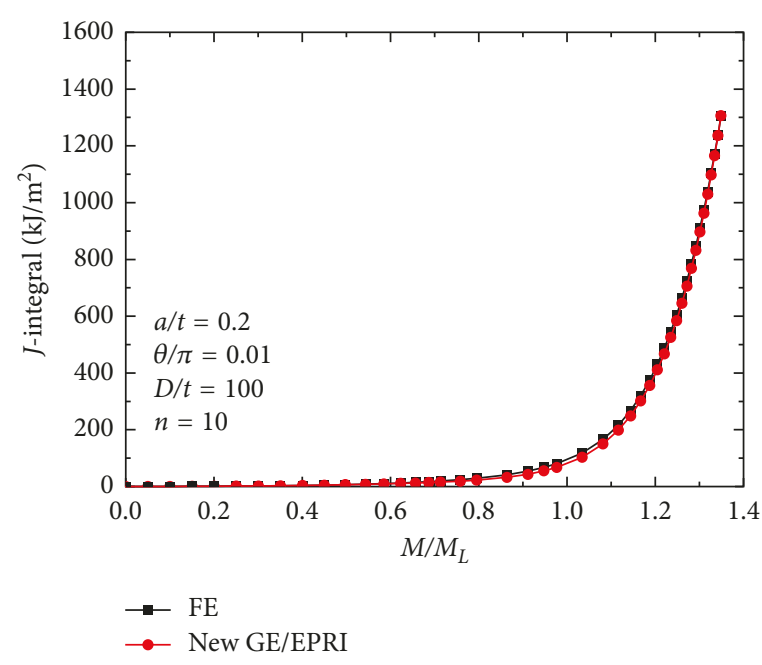

(a)

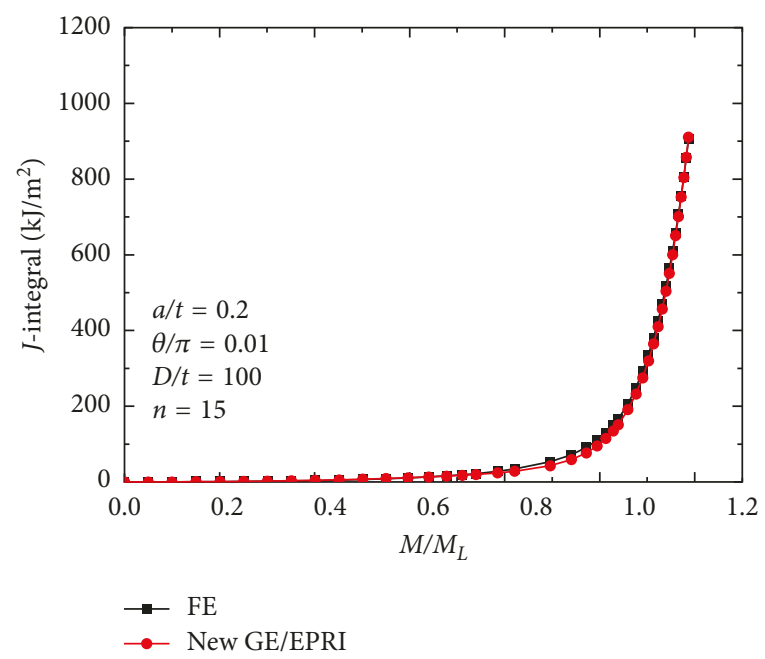

(b)

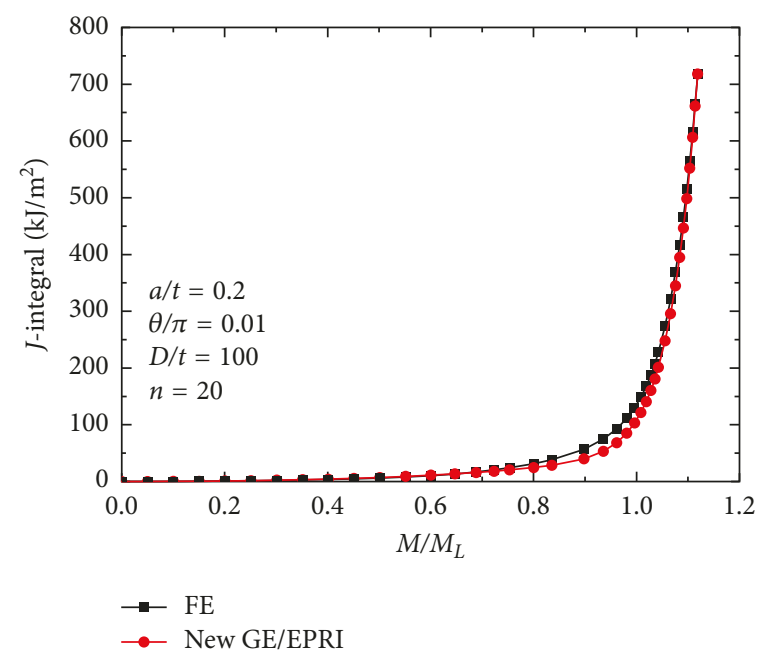

(c)

FIgURE 8: Comparison of $J$-integral estimated by using new elastic and plastic influence functions with FE results for thin-walled pipes under bending having $D / t=100, a / t=0.2$, and $\theta / \pi=0.01$ : (a) $n=10$; (b) $n=15$; (c) $n=20$. 


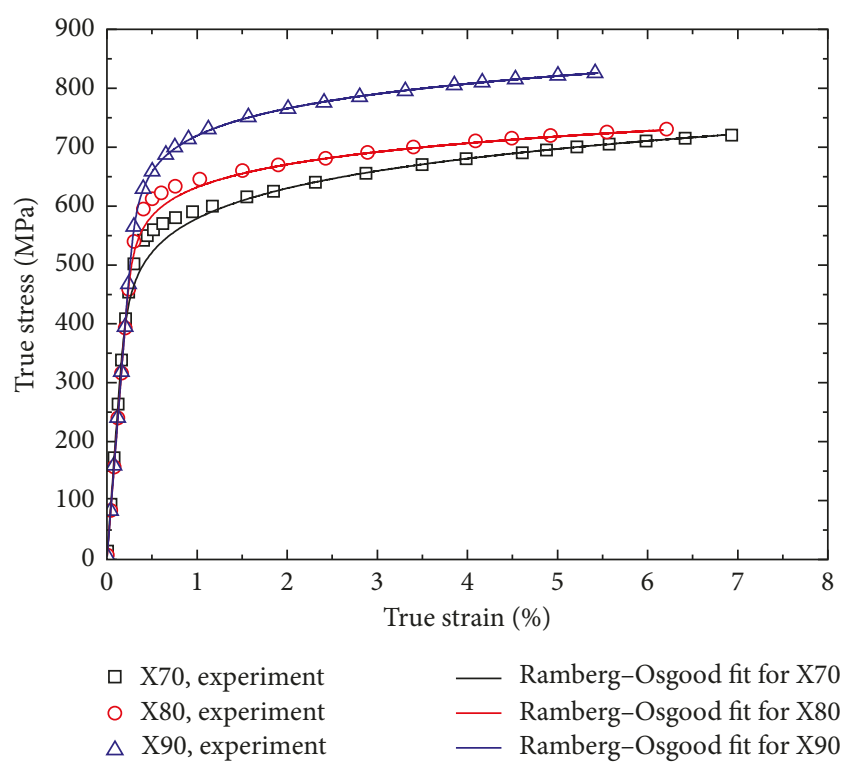

FIgURE 9: True stress-strain curves for pipeline steels.

TABLE 5: Tensile properties of pipeline steels at room temperature in the FE analysis.

\begin{tabular}{lcccc}
\hline Material & $E(\mathrm{GPa})$ & $\sigma_{0}(\mathrm{MPa})$ & $\alpha$ & $n$ \\
\hline X70 & 214 & 552 & 1.76 & 10 \\
X80 & 197 & 614 & 1.42 & 15 \\
X90 & 197 & 666 & 0.59 & 15 \\
\hline
\end{tabular}

4.2. Application for Pipeline Steels. To show the effectiveness of proposed J-integral estimation solutions, additional elastic-plastic three-dimensional FE analyses are performed. The FE procedures are similar to those in Section 3, except material properties. For validation in the pipeline industries, experimental true stress-strain data for the three different materials API 5L X70, X80, and X90 at the room temperature are considered, instead of idealized Ramberg-Osgood materials. Figure 9 shows the experimental true stress-strain data by uniaxial tension for the three materials. The entire true stress-strain data up to the ultimate tensile strength are fitted to determine the Ramberg-Osgood constants in (1). The best combination of $\alpha$ and $n$ can be firstly obtained by least-squares fit to the experimental data for one pipeline. It is found that $n$ approaches 10 for X70 steel and 15 for X80 and X90 steels. Then, the values of $n$ are fixed to 10 for X70 steel and 15 for X80 and X90 steels; the corresponding values of $\alpha$ are obtained by least-squares fit method. The resulting Ramberg-Osgood fitting parameters are listed in Table 5, and the fitted Ramberg-Osgood curves are rather satisfactory as shown in Figure 9.

For a given material, the experimental true stress-plastic strain data are directly adopted in the FE analysis and thinwalled pipes with $D / t=100, a / t=0.2$, and $\theta / \pi=0.04$. FE results are extracted by the method described in Section 3. The material parameters listed in Table 5 and values of $F$ and $h_{1}$ given in Section 4.1 are used to estimate the J-integral. Figure 10 compares the estimated J-integral with FE results

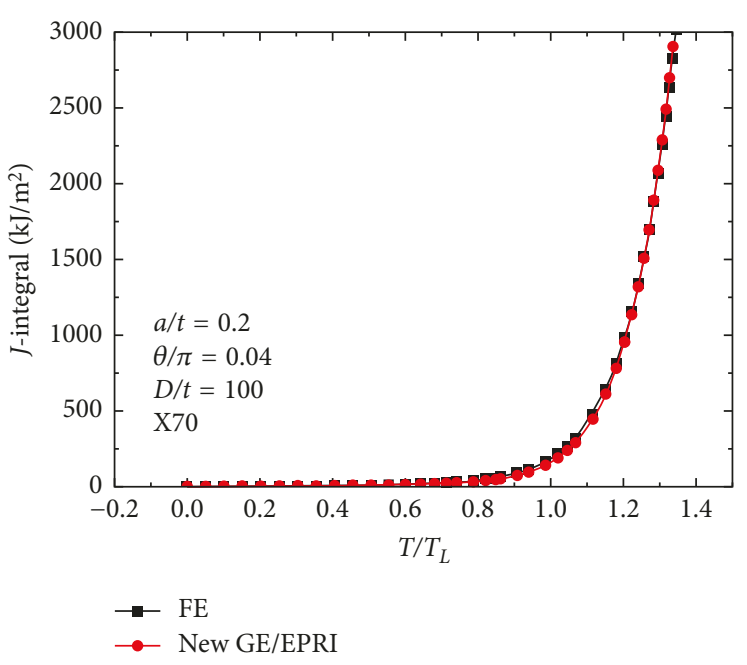

(a)

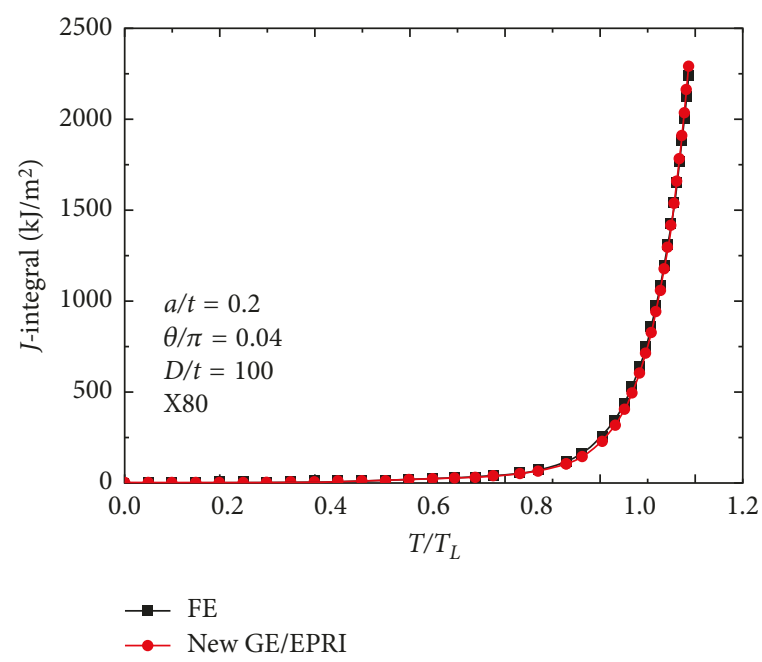

(b)

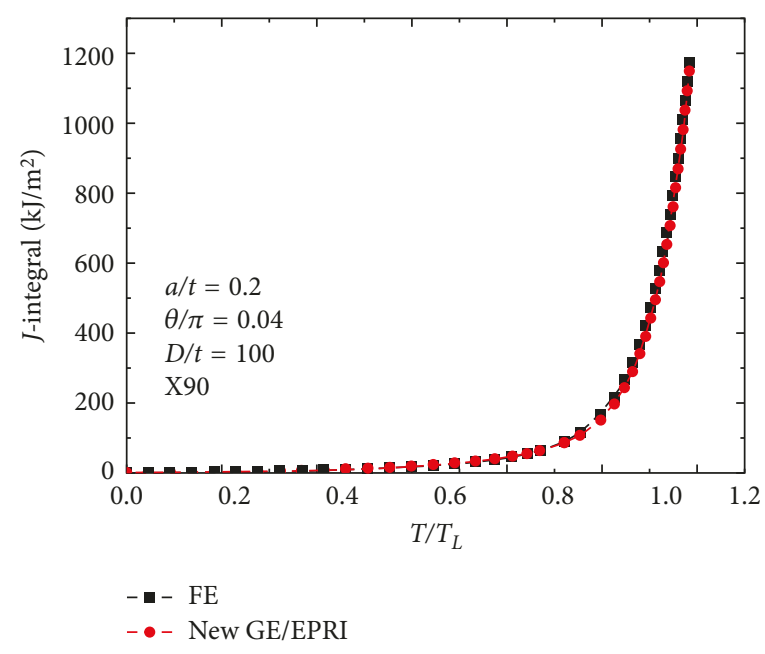

(c)

FIGURE 10: Comparison of J-integral estimated by using new elastic and plastic influence functions with FE results for thin-walled pipes under tension having $D / t=100, a / t=0.2$, and $\theta / \pi=0.04$ : (a) X70; (b) X80; (c) X90. 


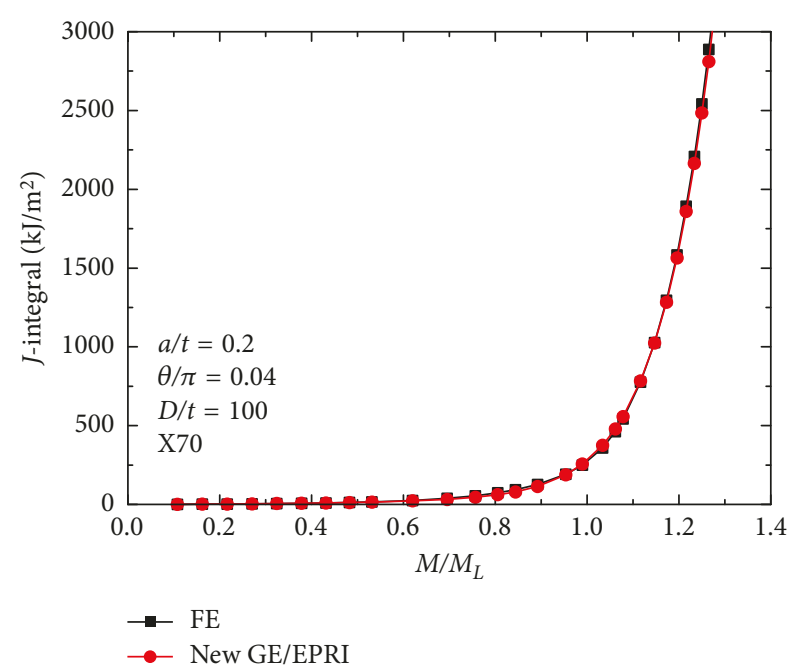

(a)

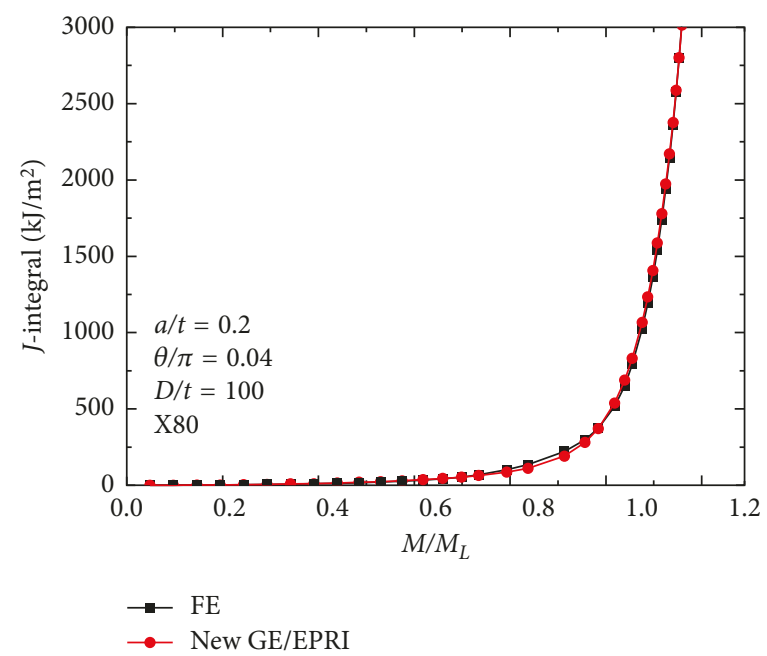

(b)

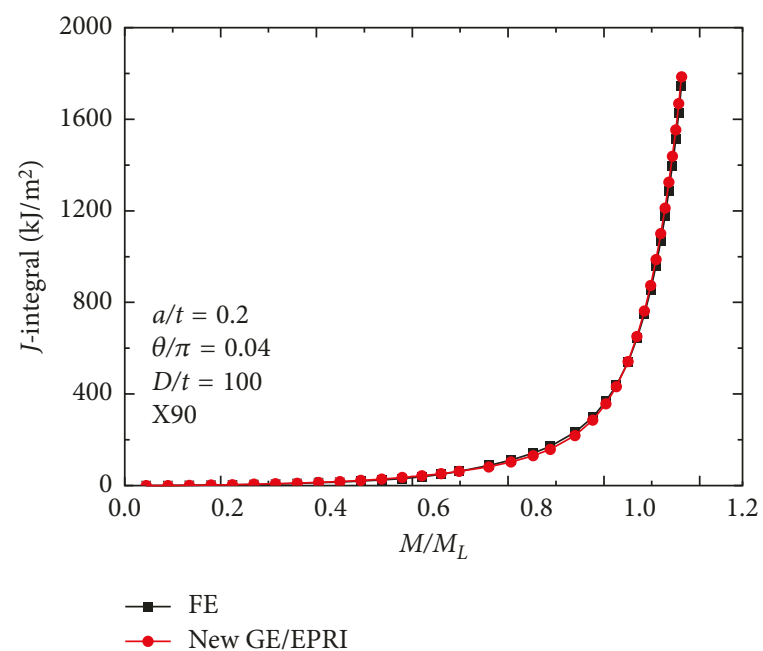

(c)

FIGURE 11: Comparison of $J$-integral estimated by using new elastic and plastic influence functions with FE results for thin-walled pipes under bending having $D / t=100, a / t=0.2$, and $\theta / \pi=0.04$ : (a) X70; (b) X80; (c) X90. for pipes under tension. Figure 11 provides similar results for pipes under bending. Excellent agreement shows that the newly proposed elastic and plastic influence functions can be successfully used to predict $J$-integrals in pipeline industries.

\section{Conclusions}

Applicability of J-estimation solutions based upon GE/EPRI approach was extended to thin-wall high-strength pipelines with small circumferential surface cracks, subject to tension and bending loads. Attention is directed to thin-walled highstrength steels in the oil and gas transportation system, which have relatively high strain-hardening exponent. Size of the small cracks with constant depth considered in this work covers the range of practical interest in the welded pipelines.

Three-dimensional FE analyses are conducted for the circumferentially cracked pipes with different crack geometries and material properties. By FE analyses for idealized Ramberg-Osgood materials, values of the new elastic influence function $F$ for stress intensity factor and the new plastic influence function $h_{1}$ for fully plastic $J$ solutions are tabulated as a function of crack depth-to-thickness ratio $a / t$, normalized crack length $\theta / \pi$, and mean diameter-tothickness ration $D / t$. The proposed $J$-estimation solutions are validated against three-dimensional FE analyses by using experimental stress-strain data for three typical pipeline steels. Based on the excellent agreement between the $J$-estimation solution and the FE analyses, it is found that the proposed $J$-estimation solutions can be successfully used to predict the J-integral for the high-strength pipelines with small circumferential surface cracks under tension and bending loads.

\section{Nomenclature}

a: $\quad$ Crack depth

$a_{e}: \quad$ Effective crack length

$b$ : Uncracked ligament

$c$ : Half-length for a crack

$D$ : Mean diameter of a pipe

E: Young's modulus

$E^{\prime}$ : "Effective" Young's modulus

F: $\quad$ Elastic influence function for elastic stress intensity factor

$h_{1}$ : $\quad$ Plastic influence function for $J_{p}$ in the GE/EPRI method

$I_{n}: \quad$ Integration constant for HRR fields

J: J-integral

$J_{e}: \quad$ Elastic component of $J$-integral

$J_{p}: \quad$ Plastic component of $J$-integral

$K: \quad$ Elastic stress intensity factor

$L$ : Half-length of a pipe

$M$ : Bending moment

$M_{L}$ : Plastic limit bending moment

$n$ : $\quad$ Strain-hardening exponent

$P$ : $\quad$ Generalized load

$P_{L}$ : $\quad$ Plastic limit load of a cracked pipe

$P_{\text {ref }}$ : Reference load of a cracked pipe 


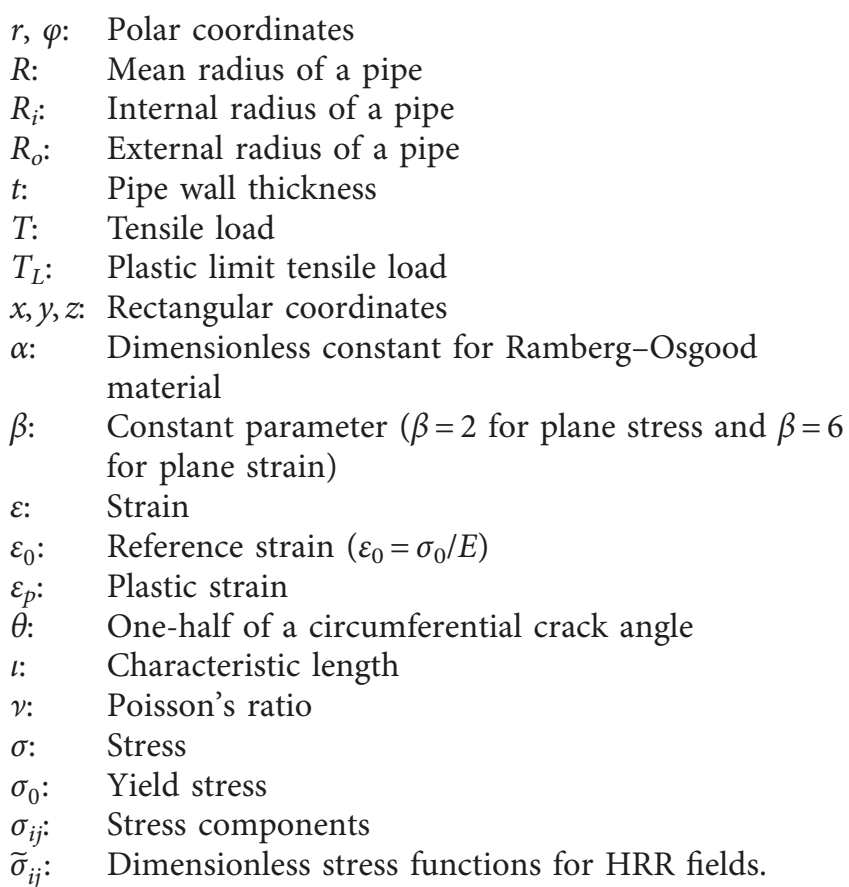

\section{Conflicts of Interest}

The authors declare that there are no conflicts of interest regarding the publication of this paper.

\section{Acknowledgments}

This work was supported by the National Key Research and Development Program of China (no. 2017YFB0702003), the Nature Science Foundation of China (Grant nos. 11132011, 11472287, and 11572324), the Key Research Program of Frontier Sciences (Grant no. QYZDJSSW-JSC011), the Strategic Priority Research Program of the Chinese Academy of Sciences (Grant nos. XDB22040302 and XDB22040303), and the CAS-SAFEA International Partnership Program for Creative Research Teams.

\section{References}

[1] B. Tanguy, T. T. Luu, G. Perrin, A. Pineau, and J. Besson, "Plastic and damage behaviour of a high strength X100 pipeline steel: experiments and modelling," International Journal of Pressure Vessels and Piping, vol. 85, no. 5, pp. 322-335, 2008.

[2] Y. Terada, H. Tamehiro, H. Morimoto et al., "X100 linepipe with excellent HAZ toughness and deformability," ASME Conference Proceedings, vol. 2003, no. 36835, pp. 287-294, 2003.

[3] C. F. Shih and J. W. Hutchinson, "Fully plastic solutions and large-scale yielding estimates for plane stress crack problems," Journal of Engineering Materials and Technology, vol. 98, no. 4, pp. 289-295, 1976.

[4] V. Kumar, M. D. German, and C. F. Shih, "An engineering approach for elastic-plastic fracture analysis," EPRI Report NP-1931, Electric Power Research Institute, Palo Alto, CA, USA, 1981.
[5] A. Zahoor, "Ductile fracture handbook," EPRI Report NP-6301-D, Electric Power Research Institute, Palo Alto, CA, USA, 1989.

[6] M. S. G. Chiodo and C. Ruggieri, "J and CTOD estimation procedure for circumferential surface cracks in pipes under bending," Engineering Fracture Mechanics, vol. 77, no. 3, pp. 415-436, 2010.

[7] J. Foxen and S. Rahman, "Elastic-plastic analysis of small cracks in tubes under internal pressure and bending," Nuclear Engineering and Design, vol. 197, no. 1-2, pp. 75-87, 2000.

[8] V. Kumar, M. D. German, W. W. Wilkening, W. R. Andrews, H. G. Delorenzi, and D. F. Mowbray, "Advances in elasticplastic fracture analysis," EPRI Report NP-3607, Electric Power Research Institute, Palo Alto, CA, USA, 1984.

[9] V. Kumar and M. D. German, "Elastic-plastic fracture analysis of through-wall and surface flaws in cylinders," EPRI Report NP-5596, Electric Power Research Institute, Palo Alto, CA, USA, 1988.

[10] M. Paredes and C. Ruggieri, "Engineering approach for circumferential flaws in girth weld pipes subjected to bending load," International Journal of Pressure Vessels and Piping, vol. 125, pp. 49-65, 2015.

[11] R. Mohan, A. Krishna, F. W. Brust, and G. M. Wilkowski, "J-estimation schemes for internal circumferential and axial surface cracks in pipe elbows," Journal of Pressure Vessel Technology, vol. 120, no. 4, pp. 418-423, 1998.

[12] J. Chattopadhyay, A. K. S. Tomar, B. K. Dutta, and H. S. Kushwaha, "Elastic-plastic J and COD estimation schemes for throughwall circumferentially cracked elbow under in-plane closing moment," Engineering Fracture Mechanics, vol. 72, no. 14, pp. 2186-2217, 2005.

[13] J. Chattopadhyay, "Improved J and COD estimation by GE/EPRI method in elastic to fully plastic transition zone," Engineering Fracture Mechanics, vol. 73, no. 14, pp. 1959-1979, 2006.

[14] L. F. S. Parise, C. Ruggieri, and N. P. O’Dowd, "Fully-plastic strain-based J estimation scheme for circumferential surface cracks in pipes subjected to reeling," Journal of Pressure Vessel Technology, vol. 137, no. 4, p. 041204, 2015.

[15] R. A. Ainsworth, "The assessment of defects in structures of strain hardening material," Engineering Fracture Mechanics, vol. 19, no. 4, pp. 633-642, 1984.

[16] Y. J. Kim, J. S. Kim, Y. Z. Lee, and Y. J. Kim, "Non-linear fracture mechanics analyses of part circumferential surface cracked pipes," International Journal of Fracture, vol. 116, no. 4, pp. 347-375, 2002.

[17] Y. J. Kim, and P. J. Budden, "Reference stress approximations for $\mathrm{J}$ and $\mathrm{COD}$ of circumferential through-wall cracked pipes," International Journal of Fracture, vol. 116, no. 3, pp. 195-218, 2002.

[18] Y. J. Kim, J. S. Kim, Y. J. Park, and Y. J. Kim, "Elastic-plastic fracture mechanics method for finite internal axial surface cracks in cylinders," Engineering Fracture Mechanics, vol. 71, no. 7-8, pp. 925-944, 2004.

[19] N. H. Kim, C. S. Oh, Y. J. Kim, J. S. Kim, D. W. Jerng, and P. J. Budden, "Limit loads and fracture mechanics parameters for thick-walled pipes," International Journal of Pressure Vessels and Piping, vol. 88, no. 10, pp. 403-414, 2011.

[20] D. H. Cho, H. B. Seo, Y. J. Kim, Y. S. Chang, M. J. Jhung, and Y. H. Choi, "Advances in J-integral estimation of circumferentially surface cracked pipes," Fatigue \& Fracture of Engineering Materials \& Structures, vol. 34, no. 9, pp. 667-681, 2011. 
[21] J. S. Park, Y. H. Choi, and S. Im, "Generation of plastic influence functions for J-integral and crack opening displacement of thin-walled pipes with a short circumferential through-wall crack," International Journal of Pressure Vessels and Piping, vol. 117-118, pp. 17-24, 2014.

[22] D. H. Cho, S. W. Woo, Y. S. Chang et al., "Enhancement of J estimation for typical nuclear pipes with a circumferential surface crack under tensile load," Journal of Mechanical Science and Technology, vol. 24, no. 3, pp. 681-686, 2010.

[23] K. R. Jayadevan, E. Østby, and C. Thaulow, "Fracture response of pipelines subjected to large plastic deformation under tension," International Journal of Pressure Vessels and Piping, vol. 81, no. 9, pp. 771-783, 2004.

[24] API 1104, Welding of Pipelines and Related Facilities, American Petroleum Institute, Washington, DC, USA, 2013.

[25] G. R. Irwin, "Plastic zone near a crack and fracture toughness," Sagamore Research Conference Proceedings, vol. 4, pp. 63-78, 1961.

[26] T. L. Anderson, Fracture Mechanics: Fundamentals and Applications, CRC Press, Boca Raton, FL, USA, 2005.

[27] A. A. Ilyushin, "The theory of small elastic-plastic deformations," Prikadnaia Matematica i Mekhanika, vol. 10, pp. 347-353, 1946, in Russian.

[28] Y. J. Kim, D. J. Shim, K. Nikbin, Y. J. Kim, S. S. Hwang, and J. S. Kim, "Finite element based plastic limit loads for cylinders with part-through surface cracks under combined loading," International Journal of Pressure Vessels and Piping, vol. 80, no. 7-8, pp. 527-540, 2003.

[29] DNV-RP-F108, Fracture Control for Pipeline Installation Methods Introducing Cyclic Plastic Strain, Det Norske Veritas, Oslo, Norway, 2006.

[30] N. Nourpanah and F. Taheri, "Ductile crack growth and constraint in pipelines subject to combined loadings," Engineering Fracture Mechanics, vol. 78, no. 9, pp. 2010-2028, 2011.

[31] N. Mostaghel and R. A. Byrd, "Inversion of Ramberg-Osgood equation and description of hysteresis loops," International Journal of Non-Linear Mechanics, vol. 37, no. 8, pp. 1319-1335, 2002. 


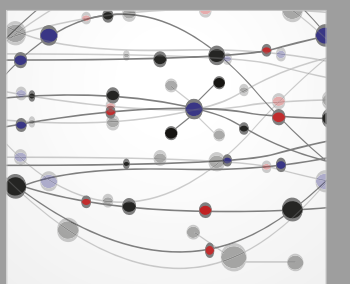

The Scientific World Journal
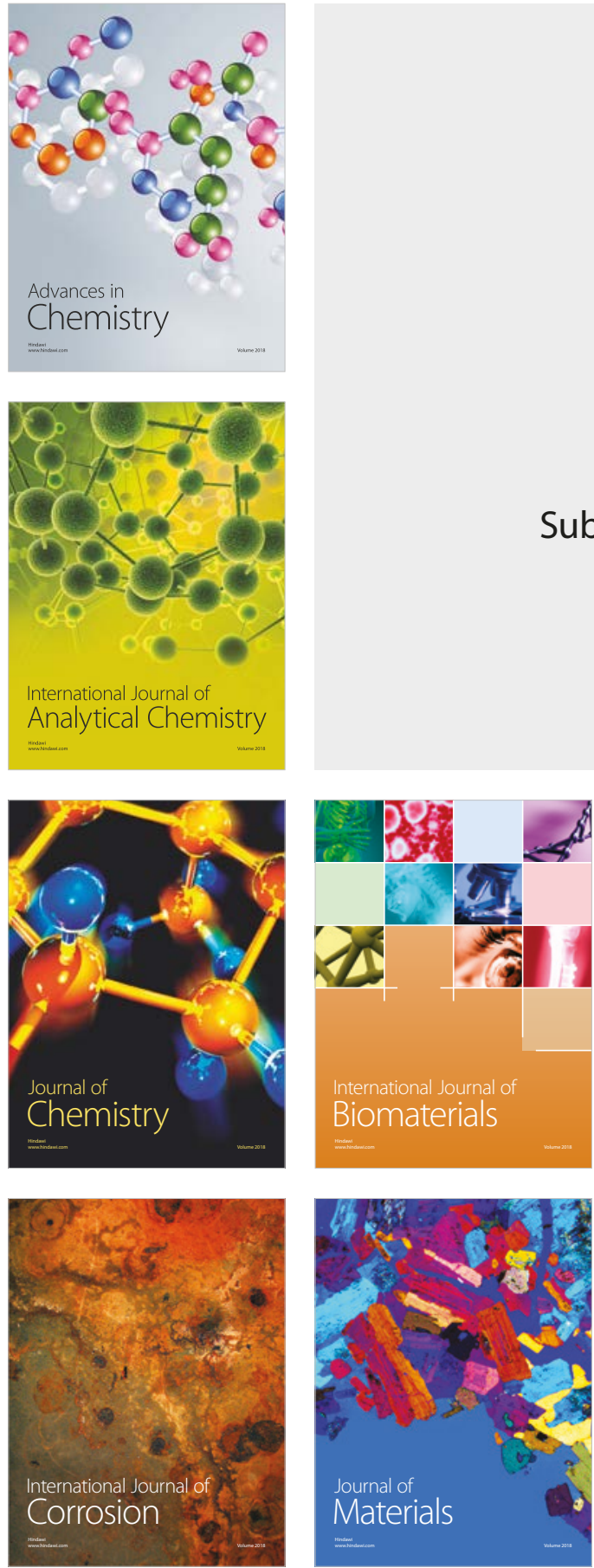

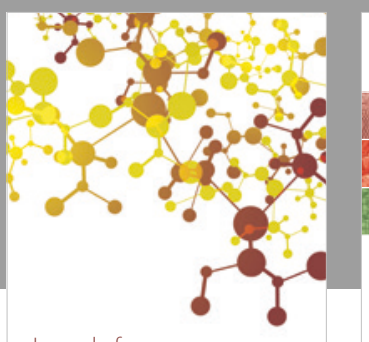

Journal of

Applied Chemistry
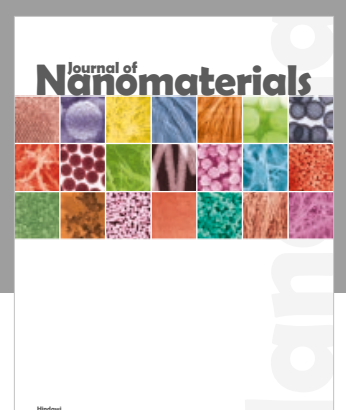

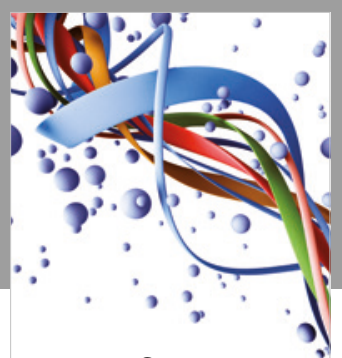

Scientifica

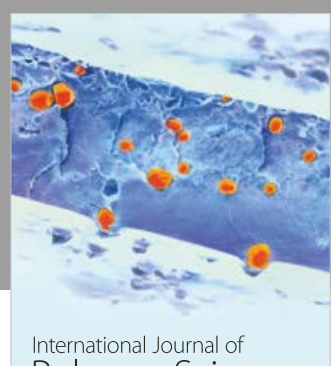

Polymer Science

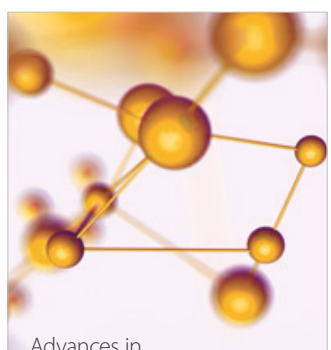

Physical Chemistry
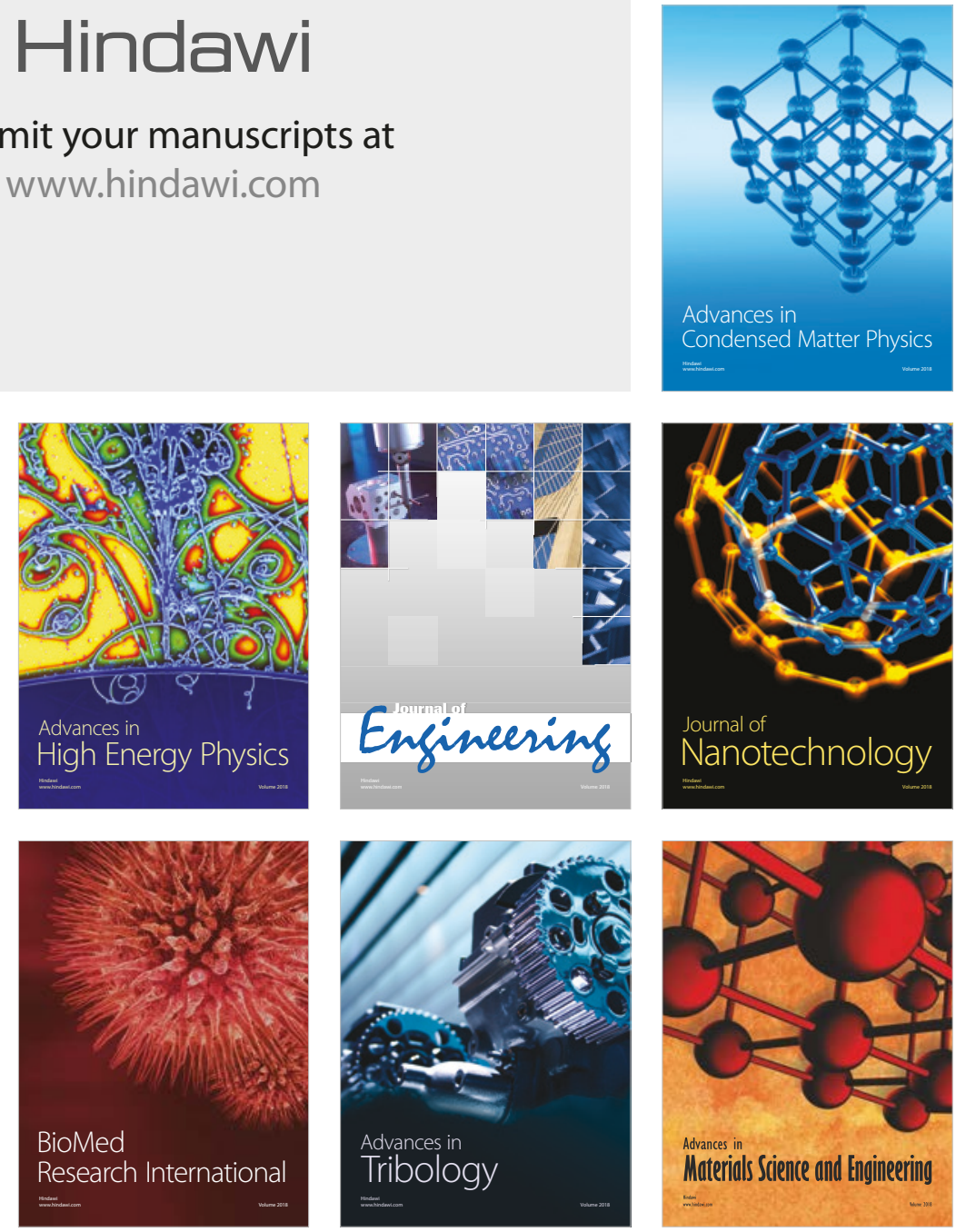